\title{
The effect of continuous intraabdominal nebulization of lidocaine during gynecological laparoscopic procedures- a pilot study
}

\author{
Avishalom Sharon • Irina Hirsh • Yuval Kaufman • \\ Ludmila Ostrovski • Orly Brandes-Klein • \\ Doron Spiegel • Alexander Shenderey • Arie Lissak
}

Received: 17 June 2007 / Accepted: 7 February 2008 /Published online: 5 March 2008

(C) Springer-Verlag 2008

\begin{abstract}
Although laparoscopic surgery is known to cause less postoperative pain when compared to laparotomy, some patients still suffer from excessive pain, especially during the first stages of recovery. The purpose of our study was to assess the effect of intraperitoneal nebulization of lidocaine during gynecological laparoscopic procedures on perioperative pain. The study was a prospective, randomized, double-blinded, placebo-controlled trial (Canadian task force classification I) that included 23 patients who underwent outpatient gynecological laparoscopic procedures. Patients were randomly assigned either to a study group that received $5 \mathrm{mg} / \mathrm{kg}$ of lidocaine intraperitonealy during surgery $(\mathrm{n}=15)$ or to a control group that received sterile water in the same manner $(n=8)$. The fluid was infuslated along with the $\mathrm{CO}_{2}$ through a Insuflow ${ }^{\circledR}$ device. All patients received the same anesthetic technique. Intraoperative pain as assessed by changes in the vital signs was treated with fentanyl. Postoperative pain was evaluated according to postoperative opioid requirements and by the Visual Analogue Scale (VAS) at $15 \mathrm{~min}, 1 \mathrm{~h}$ and $24 \mathrm{~h}$ postoperatively. The VAS score was found to be lower for the study group $1 \mathrm{~h}$ after surgery $(\mathrm{p}=0.023)$. There was no difference in the VAS scores at $15 \mathrm{~min}(\mathrm{p}=0.9)$ and $24 \mathrm{~h}$ $(p=0.11)$ after surgery. A correlation analysis showed no association between the amount of lidocaine insufflated and
\end{abstract}

\footnotetext{
A. Sharon $(\varangle) \cdot$ I. Hirsh • Y. Kaufman · L. Ostrovski •

O. Brandes-Klein $\cdot$ A. Shenderey $\cdot$ A. Lissak

Carmel Medical Center,

Haifa, Israel

e-mail: sharondr@gmail.com

D. Spiegel

Bnei Zion Medical Center,

Haifa, Israel
}

the severity of the postoperative pain. There was no difference in terms of fentanyl administration during surgery or opiod consumption following surgery between the groups. We concluded that continuous intraperitoneal insuflation of lidocaine using an Insuflow ${ }^{\circledR}$ device may significantly reduce pain in the initial stage of postoperative recovery.

Keywords Laparoscopy $\cdot$ Lidocaine $\cdot$ Nebulizer $\cdot$ Pain

\section{Introduction}

Gynecological laparoscopic procedures have become increasingly popular mainly due to lower perioperative morbidity, less postoperative pain and shorter hospitalizations when compared to laparotomy. But despite the reduction in postoperative pain, it may be moderate to severe for some patients with up to $80 \%$ of patients still requiring opioid analgesia following laparoscopy [1]. Pain following laparoscopy is comprised of visceral, parietal and referred shoulder pain. It may be influenced by several factors including the type and length of operation as well as subjective pain perception by the patient. The physical properties of the insuflated gas may also be a cause for postoperative pain including the type of gas $\left(\mathrm{CO}_{2}\right.$ or $\left.\mathrm{N}_{2} \mathrm{O}\right)$, temperature, humidity and the total amount of insuflated gas. Gas that is dry and cold was found to increase visceral pain following laparoscopy [2]. Shoulder pain is thought to be referred through the phrenic nerve and is probably secondary to diaphragmatic irritation caused by pneumoperitoneum. It can be found postoperatively in $35-60 \%$ of patients [3-5].

The purpose of our study was to assess the effect of intraperitoneal nebulization of lidocaine during gynecolog- 
ical laparoscopic procedures on perioperative pain. The study is a prospective, randomized, double-blinded, placebo-controlled trial (Canadian task force classification I) and defined as a pilot study with a relatively small number of patients.

\section{Materials and methods}

The study included 23 patients undergoing elective gynecological laparoscopic procedures at the day care ambulatory gynecoendoscopic unit in Carmel Medical Center. The recruited patients were above the age of 18 and had an ASA (American Society of Anesthesiologists) physical status grade of 1 to 2 . The study was approved by the hospital Helsinki Ethics Committee as well as the Israeli Ministry of Health.

All patients received the same standard anesthetic technique and standard monitoring including electrocardigram, noninvasive blood pressure measurements, end tidal $\mathrm{CO}_{2}$, oxygen saturation and temperature. Anesthesia was induced with $4 \mathrm{mg} / \mathrm{kg}$ of penthotal, $1 \mathrm{mg} / \mathrm{kg}$ of fentanyl and $0.5 \mathrm{mg}$ of droperidol. An esmeron dose of $0.6 \mathrm{mg} / \mathrm{kg}$ was given to facilitate intubation of the trachea. During surgery, the patient was monitored for signs of insufficient analgesia, including an increase of the mean arterial pressure or heart rate by $20 \%$. In this case a $1-\mathrm{mg} / \mathrm{kg}$ dose of fentanyl was administered every $10 \mathrm{~min}$ until adequate analgesia was achieved. Anesthesia was maintained with $1 \mathrm{MAC}$ (maximal alveolar concentration) isoflurane as well as a combination of $60 \% \mathrm{~N}_{2} \mathrm{O}$ and $40 \% \mathrm{O}_{2}$. Minute ventilation was controlled and adjusted to keep the end-tidal $\mathrm{CO}_{2}$ around $40 \mathrm{mmHg}$. A suppository of $100 \mathrm{mg}$ diclofenac was administered after induction of anesthesia.

Nebulization was performed by a dedicated insuflator (Fig. 1) normally used to warm and humidify the $\mathrm{CO} 2$ gas

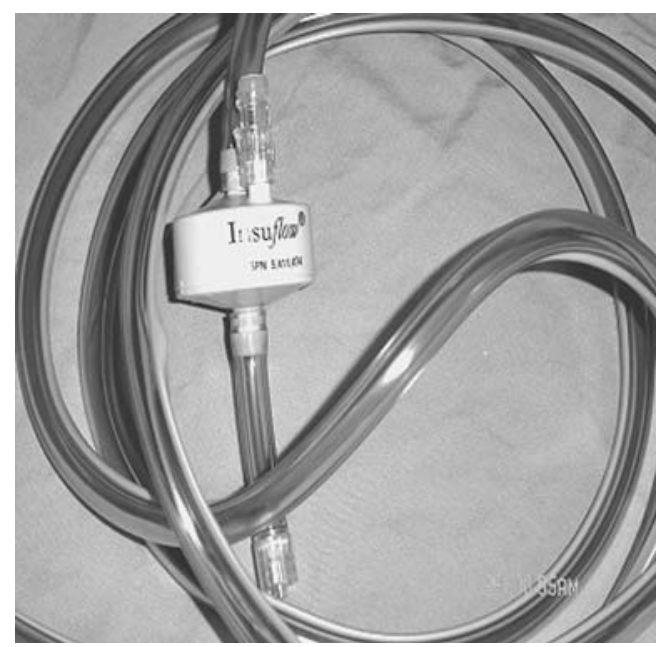

Fig. 1 Nebulization performed by a dedicated insuflator during laparoscopic procedures (Insuflow, Lexion, St Paul, $\mathrm{MN})$.

The device delivers a total of $10 \mathrm{ml}$ of fluid during insuflation of 1501 of $\mathrm{CO} 2$. In our study it was used to administer lidocaine into the peritoneal cavity.

Patients were randomly designated to the study and control groups by a computer-generated algorithm. Each patient was assigned an ampoule that was prepared according to a double-blind design by the chief pharmacist in the hospital. The content of the ampoule was known only to the chief pharmacist. Each ampoule contained a total of $10 \mathrm{ml}$ of fluid. Ampoules asigned for the study group patients contained a weight-dependent dose of lidocaine of $5 \mathrm{mg} / \mathrm{kg}$ with a maximum of $300 \mathrm{mg}$ per patient. The lidocaine was then diluted with sterile water to a total of $10 \mathrm{ml}$. Patients in the control group were allocated $10 \mathrm{ml}$ of sterile water. For each patient, the blinded content of the ampoule was injected into the insuflator. During insuflation the total amount of insuflated gas was recorded, and an extrapolation of the total amount of lidocaine insuflated to the study group patients was done according to the following equation:

\section{Total amount of insuflated lidocaine $(\mathrm{mg})=$ Total amount of lidocaine injected into the insulfator $(\mathrm{mg})^{*}$ amount of insuflated gas $(L) / 150 L$.}

Therefore, the total amount of insuflated lidocaine depended on the initial concentration of the fluid injected into to the insuflator and the total amount of insuflated $\mathrm{CO} 2$.

During laparoscopy, an intraabdominal pressure was automatically maintained at a maximum of $15 \mathrm{mmHg}$ and flow at a maximum of $3.5 \mathrm{l} / \mathrm{min}$. The Insuflow device was used instead of the standard insuflation tube and was connected directly to the Veress needle or to the trocar. Serum levels of lidocaine were measured after 15, 60 and $120 \mathrm{~min}$ from initiation of lidocaine administration.

In order to reduce wound pain, $10 \mathrm{ml}$ of $0.5 \%$ bupivacaine was injected subcutaneously at the incision sites.

All operations were performed uniformly, under general anesthesia with the patient in a lithotomy position. An indwelling urinary catheter was placed and urine production monitored. A Veress needle was inserted through a subumbilical $1-\mathrm{cm}$ cutaneous incision. After achieving pneumoperitoneum, the Veress needle was replaced by a $10-\mathrm{mm}$ trocar. Following a thorough inspection of the pelvis and abdomen, two other trocars were placed under vision. A 5-mm trocar was inserted in the left lower abdomen, about $3 \mathrm{~cm}$ above the anterior superior iliac spine (ASIS), and lateral to the superficial inferior epigastric artery. A 5- or 10-mm trocar was inserted at the midline suprapubic area. At the end of the procedure, $10-\mathrm{mm}$ fascial 
Table 1 Patient demographics and operative data

\begin{tabular}{llll}
\hline Characteristics & Study group $(\mathrm{n}=15)$ & Control group $(\mathrm{n}=8)$ & P value \\
\hline Age (years): mean \pm SD & $38 \pm 12$ & $33 \pm 16$ & 0.19 \\
Median (range) & $33(22-60)$ & $27(21-70)$ & \\
Weight (kg): mean \pm SD & $75 \pm 17$ & $66 \pm 17$ & 0.19 \\
Median (range) & $75(51-107)$ & $66(46-100)$ & 0.5 \\
Total insufflated CO2 (liters): & $19.5 \pm 17$ & $17.6 \pm 5.5$ & \\
$\quad$ mean \pm SD & $10.7(2.5-68)$ & $17.4(11.5-26)$ & 0.51 \\
Median (range) & $32 \pm 23$ & $24 \pm 10$ & \\
Surgery duration (min): mean \pm SD & $30(3-102)$ & $22(15-40)$ & \\
Median (range) & & & \\
\end{tabular}

incisions were sutured with 0 vicryl followed by $3-0$ vicryl sutures for skin incisions.

Postoperative pain was evaluated using the Visual Analogue Scale (VAS) at $15 \mathrm{~min}, 1 \mathrm{~h}$ and $24 \mathrm{~h}$ from termination of surgery. The amount and type of analgesia consumed by the patient were also used to determine postoperative pain.

In the recovery room, when the VAS score exceeded 4, the patient was given an intravenous dose of $0.05 \mathrm{mg} / \mathrm{kg}$ morphine. If necessary, repeated doses were given until adequate pain relief was achieved. Tremor was treated with $15 \mathrm{mg}$ of IV pethidine and postoperative nausea and vomiting with $10 \mathrm{mg}$ of IV pramin.

Statistical analysis included baseline characteristics and postoperative VAS scores that were compared using the non-parametric Mann-Whitney test. The non-parametric test was chosen because of the ordinarily nature of this variable and relatively small sample size. VAS distribution of the two groups was presented using box plots. Correlations between the amount of insuflated lidocaine and VAS scores were tested using Spearman correlation coefficients at each time point. All tests were two-sided with a significance level of 0.05 . Analyses were performed using SPSS (version 11.5) statistical software (SPSS Inc., Chicago, IL).

\section{Results}

Demographic analysis and operative data showed no statistically significant differences between the two groups (Table 1). The laparoscopic procedures that were done are shown in Table 2.

There was no significant difference between the study and control groups with regards to surgery duration $(32 \pm 23 \mathrm{~min}$ and $24 \pm 10 \mathrm{~min}$, respectively, $\mathrm{p}=0.51$ ).

The mean amount of total insufflated $\mathrm{CO}_{2}$ was similar between the two groups (19.5 1 in the study groups and 17.61 in the control group, $\mathrm{p}=0.5$ ).

The mean amount of lidocaine administered during surgery to the study group patients was $38 \mathrm{mg}$. Serum lidocaine levels that were measured $15 \mathrm{~min}, 1 \mathrm{~h}$ and $2 \mathrm{~h}$ after initiation of insuflation were all within the non-toxic range of $0.0-0.2 \mathrm{mcg} / \mathrm{ml}$.

Figure 2 demonstrates the VAS scores of each group at the different time points. A comparison of the postoperative VAS scores between the groups showed no difference at $15 \mathrm{~min}(\mathrm{p}=0.9)$. At $1 \mathrm{~h}$ postoperatively the VAS score was significantly lower for the study group than for the control group $(\mathrm{VAS}=1$ (range: $1-3)$ vs. $\mathrm{VAS}=4$ (range: $1-7), \mathrm{p}=$ 0.023 ). After $24 \mathrm{~h}$ from termination of surgery there was no significant difference between the study and control groups in terms of VAS score [VAS $=3$ (range: $0-5$ ) vs. VAS $=5$ (range: $1-8$ ) respectively, $\mathrm{p}=0.107]$. There was no correlation between the amounts of lidocaine given and the severity of postoperative pain in both groups at $15 \mathrm{~min}$, $1 \mathrm{~h}$ and $24 \mathrm{~h}$ following surgery.

Table 3 shows the Visual Analogue Scale (VAS) scores of the study and control groups at the various time intervals with respect to the administration of additional doses of fentanyl. Seven of the 15 patients from the study group $(46.7 \%)$ and 2 of the 8 patients from the control group (25\%) had received additional doses of fentanyl during surgery $(\mathrm{p}=0.4$, Fisher exact test). The mean dosage for each group was $71.4 \mathrm{mg}$ and $50 \mathrm{mg}$, respectively. For the patients who did not receive additional doses of fentanyl, a significant difference with regards to VAS scores was found between the study and control groups at $1 \mathrm{~h}$ (VAS $=1$ vs.

Table 2 The laparoscopic procedures according to study and control groups

\begin{tabular}{lll}
\hline Laparoscopic procedure & $\begin{array}{l}\text { Study group } \\
(15)\end{array}$ & $\begin{array}{l}\text { Control group } \\
(8)\end{array}$ \\
\hline Diagnostic laparoscopy & 5 & 1 \\
Ovarian cystectomy & 1 & 4 \\
Bilateral salpingo-oophorectomy & 5 & 1 \\
Salpingectomy & 0 & 1 \\
Ovarian drilling & 1 & 1 \\
Myomectomy & 1 & 0 \\
Ablation of endometriosis & 1 & 0 \\
Removal of a lost of intrauterine & 1 & 0 \\
device & & \\
\hline
\end{tabular}


Fig. 2 VAS scores of each group at the different time points
VAS Distribution by Drug and Time

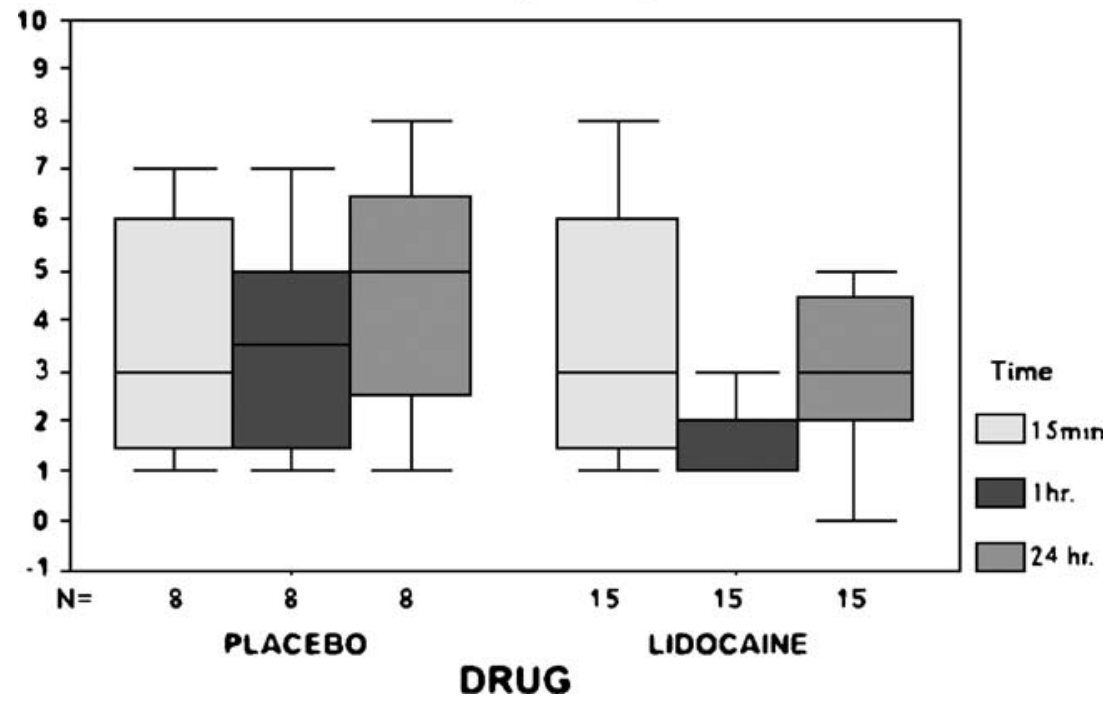

$\mathrm{VAS}=5$, respectively, $\mathrm{p}=0.011)$ and $24 \mathrm{~h}(\mathrm{VAS}=3 \mathrm{vs} . \mathrm{VAS}=6$, respectively, $\mathrm{p}=0.028$ ) after surgery.

At recovery, 7 of the 15 patients from the study group $(46.7 \%)$ and 3 of the 8 patients from the control group $(37.5 \%)$ had received morphine ( $\mathrm{p}=1$, Fisher exact test). The mean dosage was $5.9 \mathrm{mg}$ and $6.7 \mathrm{mg}$, respectively.

\section{Discussion}

The administration of local anesthetics under direct vision at the beginning of laparoscopy in the right sub-diaphragmatic peritoneum has been shown to decrease postoperative shoulder pain [6]. However, it has not been able to decrease visceral pain after laparoscopic cholecystectomy [7]. One possible cause is that visceral pain from the peritoneum is not being treated efficiently due to a non-uniform distribution of the local anesthetic in the peritoneal cavity. Therefore, insuflation of a local anesthetic during laparoscopy may allow its even distribution throughout the peritoneum.
An attempt to form an even intraperitoneal distribution of medications has been done by Reymond et al. [11]. They developed a micro-pump that has been tested on an animal model (pig) and is suitable for minimally invasive surgery. The pump delivered micro-droplets that can reach any exposed surface on the peritoneum. The problem that they encountered was that the pump stopped administering the micro-droplets when the peritoneal cavity reached $100 \%$ humidity. Therefore, the amount of administered medication was limited.

For the purpose of lidocaine insuflation, we chose the insuflow device. The insuflow has been shown to decrease perioperative pain by heating and humidifying the $\mathrm{CO}_{2}[2$, 8]. But others [9] challenge these findings by showing no pain reduction when comparing heated and humidified $\mathrm{CO} 2$ to cold and dry $\mathrm{CO}_{2}$ during gynecologic laparoscopy. The location of the heating device along the insufflating system may also be important for its success. When $\mathrm{CO}_{2}$ is heated in the insufflator device, it may lose its temperature along its way to the patient and return to room temperature before
Table 3 The Visual Analogue Scale (VAS) scores of the study and control groups at the various time intervals with respect to the administration of additional doses of fentanyl (range $=1$ to 10$)$

\begin{tabular}{|c|c|c|c|c|}
\hline VAS & $\begin{array}{l}\text { Time of } \\
\text { checking }\end{array}$ & $\begin{array}{l}\text { VAS of } \\
\text { study } \\
\text { group } \\
(\mathrm{n}=15)\end{array}$ & $\begin{array}{l}\text { VAS of } \\
\text { control } \\
\text { group } \\
(\mathrm{n}=8)\end{array}$ & $\begin{array}{l}\mathrm{P} \\
\text { value }\end{array}$ \\
\hline \multirow{3}{*}{$\begin{array}{l}\text { VAS score for patients who did not receive additional doses } \\
\text { of fentanyl during surgery Study group-8 patients, control } \\
\text { group-6 patients }\end{array}$} & $15 \mathrm{~min}$ & 3 & 4 & NS \\
\hline & $60 \mathrm{~min}$ & 1 & 5 & 0.011 \\
\hline & $24 \mathrm{~h}$ & 3 & 6 & 0.028 \\
\hline \multirow{3}{*}{$\begin{array}{l}\text { VAS for patients who did receive additional doses of } \\
\text { fentanyl during surgery Study group- } 7 \text { patients (mean } \\
\text { dose }=71.4 \mathrm{mg} \text { ), control group-2 patients (mean } \\
\text { dose }=50 \mathrm{mg} \text { ) }\end{array}$} & $15 \mathrm{~min}$ & 3 & 2 & NS \\
\hline & $60 \mathrm{~min}$ & 2 & 2 & NS \\
\hline & $24 \mathrm{~h}$ & 3 & 2 & NS \\
\hline
\end{tabular}


reaching its destination, thus losing the potential heating effect $[5,10]$.

Using lidocaine instead of sterile water may have both a humidifying as well as a direct anesthetic effect. It may also have a possible central effect if the lidocaine is absorbed systemically through peritoneal blood vessels. Our study found no detectable levels of lidocaine in the serum of the patients and therefore no evidence of systemic absorbance when administering an average of $38 \mathrm{mg}$ intraperitonealy.

Our study showed a significant reduction in postoperative pain as measured by VAS score $1 \mathrm{~h}$ after termination of laparoscopy when lidocaine is insufflated intraperitonealy instead of sterile water. A possible explanation for the lack of difference in postoperative pain after $15 \mathrm{~min}$ is that at the early recovery period patients might still be confused from the anesthesia and hence find it hard to accurately report on the VAS score. At this point in time analgesics such as fentanyl may still have their effect on pain. The lack of effectiveness may also be related to the low amounts of insufflated lidocaine $(38 \mathrm{mg})$ as a result of the short procedures and the insuflating device. The fact that no difference was found between the groups after $24 \mathrm{~h}$ is probably related to the short half-life of lidocaine.

One may argue about the rationale for using subcutaneous bupivacaine and rectal diclofenac and their potential influences on the results. Using too much analgesia during surgery might impinge on the potential beneficial effect of the lidocaine. Our aim was to show the effect of lidocaine on visceral pain. Subcutaneous bupivacaine was given in order to neutralize abdominal wall pain, thus preventing the patient from confusing abdominal wall as visceral pain. The administration of a diclofenac suppository was a Helsinki Committee requirement. Since all patients had received the suppository, it is an independent value, but it might decrease the margin of potential benefit from lidoaince insuflation.

Our study was set up as a pilot study aimed at analyzing the possible effect of intraperitoneal lidocaine insuflation on perioperative pain. The results demonstrate a significant reduction in the VAS score at recovery, but we believe that this effect can be enhanced by using a longer acting local anesthetic and by delivering a larger amount of the anesthetic into the peritloneum. This hypothesis is to be examined in a follow-up study.

\section{References}

1. Joris J, Cigarini I, Legrand $M$, Jacquet N, De Groote D, Franchimont P, Lamy M (1992) Metabolic and respiratory changes after cholecystectomy performed via laparotomy or laparoscopy. Br J Anaesth 69:341-345

2. Ott DE, Reich H, Love B, McCorvey R, Toledo A, Liu CY, Syed R, Kumar K (1998) Reduction of laparoscopic-induced hypothermia, postoperative pain and recovery room length of stay by preconditioning gas with the Insuflow device: a prospective randomized controlled multi-center study. J Soc Lap Surgeons 2:321-329

3. Mouton WG, Bessel JR, Otten KT, Maddern GJ (1999) Pain after laparoscopy. Surg Endosc 13:445-448

4. Edwards ND, Barclay K, Catling SJ, Martin DG, Morgan RH (1991) Day case laparoscopy: a survey of postoperative pain and an assessment of the value of Diclofenac. Anaesthesia 46:10771080

5. Collins KM, Docherty PW, Plantevin OM (1984) Postoperative morbidity following gynaecological outpatient laparoscopy. A reappraisal of the service. Anaesthesia 39:819-822

6. Narchi P, Benhamou D, Fernandez H (1991) Intraperitoneal local anaesthetic for shoulder pain after day-case laparoscopy. Lancet 338:1569-1570

7. Spielman FJ, Hulka JF, Ostiheimer GW, Mueller RA (1983) Pharmacokinetics and pharmacodynamics of local analgesia for laparoscopic tubal ligations. Am J Obstet Gynecol 146:821-824

8. Mouton WG, Naef M, Bessell JR Otten KT, Wagner HE, Maddern GJ (2001) A randomized controlled trial to determine the effect of humidified carbon dioxide $\left(\mathrm{CO}_{2}\right)$ insufflation on postoperative pain following thoracoscopic procedures. Surg Endos 15(6):579581

9. Kissler S, Haas M, Strohmeier R Schmitt H, Rody A, Kaufmann M, Siebzehnruebl E (2004) Effect of humidified and heated $\mathrm{CO}_{2}$ during gynecologic laparoscopic surgery on analgesic requirements and postoperative pain. J Am Assoc Gynecol Laparosc 11 (4): $473-477$

10. Jacobs VR, Kiechle M, Morrison JE Jr (2005) Carbon dioxide gas heating inside laparoscopic insufflators has no effect. JSLS 9 (2):208-212

11. Reymond MA, Hu B, Garcia A, Reck T, Kockerling F, Hess J, Morel P (2000) Feasibility of therapeutic pneumoperitoneum in a large animal model using a microvaporisator. Surg Endosc 14:51-55 